Article

\title{
Ball Convergence of an Efficient Eighth Order Iterative Method Under Weak Conditions
}

\author{
Janak Raj Sharma 1,*(D) Ioannis K. Argyros $2 \mathbb{D}$ and Sunil Kumar 1 \\ 1 Department of Mathematics, Sant Longowal Institute of Engineering and Technology Longowal, \\ Punjab 148106, India; sfageria1988@gmail.com \\ 2 Department of Mathematical Sciences, Cameron University, Lawton, OK 73505, USA; iargyros@cameron.edu \\ * Correspondence: jrshira@yahoo.co.in
}

Received: 15 October 2018; Accepted: 15 November 2018; Published: 17 November 2018

check for updates

\begin{abstract}
The convergence order of numerous iterative methods is obtained using derivatives of a higher order, although these derivatives are not involved in the methods. Therefore, these methods cannot be used to solve equations with functions that do not have such high-order derivatives, since their convergence is not guaranteed. The convergence in this paper is shown, relying only on the first derivative. That is how we expand the applicability of some popular methods.
\end{abstract}

Keywords: local convergence; nonlinear systems; Banach space; Fréchet-derivative

MSC: 65H10, 65J10, 41A25, 49M15

\section{Introduction}

Let $B_{1}$ and $B_{2}$ be Banach spaces and $\Omega$ be a convex subset of $B_{1}$. Further, suppose that $\mathfrak{L}\left(B_{1}, B_{2}\right)$ is the set of bounded linear operators from $B_{1}$ into $B_{2}$. In applied mathematics many problems can be modeled in the form

$$
F(x)=0,
$$

wherein F: $\Omega \subset B_{1} \rightarrow B_{2}$ is a Fréchet differentiable operator. Most of the methods for finding a solution $x_{*}$ of Equation (1) are iterative, since closed form solutions can be found only in some special cases (see $[1,2])$. In this paper, we study the local convergence of the method defined by

$$
\left\{\begin{array}{l}
y_{n}=x_{n}-F^{\prime}\left(x_{n}\right)^{-1} F\left(x_{n}\right) \\
z_{n}=y_{n}-\left(\frac{13}{4} I-Q\left(x_{n}\right)\left(\frac{7}{2} I-\frac{5}{4} Q\left(x_{n}\right)\right)\right) F^{\prime}\left(x_{n}\right)^{-1} F\left(y_{n}\right) \\
x_{n+1}=z_{n}-\left(\frac{7}{2} I-Q\left(x_{n}\right)\left(4 I-\frac{3}{2} Q\left(x_{n}\right)\right)\right) F^{\prime}\left(x_{n}\right)^{-1} F\left(z_{n}\right)
\end{array}\right.
$$

where $Q\left(x_{n}\right)=F^{\prime}\left(x_{n}\right)^{-1} F^{\prime}\left(y_{n}\right)$. Method (2) was studied in [3], when $B_{1}=B_{2}=\mathbb{R}^{m}$, where $m$ is a positive integer. The method was compared favorably to existing higher-order methods.

The eighth-order convergence of Equation (2) was shown in [3] using Taylor expansions and assumptions on $F^{(i)}, i=1,2, \ldots ., 8$. Such assumptions restrict the applicability of this method, especially since only the first derivative is used in the method. As a motivational example, define function $F$ on $\Omega=\left[-\frac{5}{2}, 2\right]$ and $B_{1}=B_{2}=\mathbb{R}$, by

$$
F(x)=\left\{\begin{array}{l}
x^{3} \log \left(\pi^{2} x^{2}\right)+x^{5} \sin \frac{1}{x}, x \neq 0 \\
0, \quad x=0
\end{array} .\right.
$$


We have that

$$
\begin{aligned}
& F^{\prime}(x)=2 x^{2}-x^{3} \cos \left(\frac{1}{x}\right)+3 x^{2} \log \left(\pi^{2} x^{2}\right)+5 x^{4} \sin \left(\frac{1}{x}\right) \\
& F^{\prime \prime}(x)=-8 x^{2} \cos \left(\frac{1}{x}\right)+2 x\left(5+3 \log \left(\pi^{2} x^{2}\right)\right)+x\left(20 x^{2}-1\right) \sin \left(\frac{1}{x}\right)
\end{aligned}
$$

and

$$
F^{\prime \prime \prime}(x)=\frac{1}{x}\left[\left(1-36 x^{2}\right) \cos \left(\frac{1}{x}\right)+x\left(22+6 \log \left(\pi^{2} x^{2}\right)+\left(60 x^{2}-9\right) \sin \left(\frac{1}{x}\right)\right)\right] .
$$

Notice that $F^{\prime \prime \prime}(x)$ is not bounded on $\Omega$, so earlier results cannot be applied. In this work, our goal is to weaken the assumptions considered in [3]. Consequently, we study the local convergence of Method (2) using hypotheses on the first Fréchet-derivative only by taking advantage of the Lipschitz continuity of the first Fréchet-derivative. There exist many studies which deal with the local and semilocal convergence of iterative methods (see, for example, [2,4-16]). In particular, relevant work can be found in [17] for the special case $B_{1}=B_{2}=\mathbb{R}$.

The rest of the paper is structured as follows. In Section 2, the local convergence analysis is studied. In the analysis, we also provide a radius of convergence, error bounds, and a uniqueness result of Method (2). Some numerical examples are presented in Section 3. Concluding remarks are given in Section 4.

\section{Local Convergence Analysis}

We shall introduce some scalar functions and parameters that appear in the local convergence of Method (2). Let $\varphi_{0}:[0,+\infty) \rightarrow[0,+\infty)$ be an increasing and continuous function satisfying $\varphi_{0}(0)=0$. Suppose that equation

$$
\varphi_{0}(t)=1,
$$

has at least one positive solution. Denote by $\delta_{0}$ the smallest such solution. Let $\varphi:\left[0, \delta_{0}\right) \rightarrow[0,+\infty)$ and $\varphi_{1}:\left[0, \delta_{0}\right) \rightarrow[0,+\infty)$ be increasing and continuous functions with $\varphi(0)=0$. Define functions $\psi_{1}$ and $\bar{\psi}_{1}$ on the interval $\left[0, \delta_{0}\right)$ by

$$
\psi_{1}(t)=\frac{\int_{0}^{1} \varphi((1-\theta) t) d \theta}{1-\varphi_{0}(t)}
$$

and

$$
\bar{\psi}_{1}(t)=\psi_{1}(t)-1 \text {. }
$$

We have $\bar{\psi}_{1}(0)=-1$ and $\bar{\psi}_{1}(t) \rightarrow \infty$ as $t \rightarrow \delta_{0}^{-}$. The intermediate value theorem assures that the equation $\bar{\psi}_{1}(t)=0$ has at least one solution in $\left(0, \delta_{0}\right)$. Denote by $r_{1}$ the smallest such solution. Suppose that the equation

$$
\varphi_{0}\left(\psi_{1}(t) t\right)=1,
$$

has at least one positive solution. Denote by $\delta_{1}$ the smallest such solution. Set $\delta_{2}=\min \left\{\delta_{0}, \delta_{1}\right\}$. Define functions $\psi_{2}$ and $\bar{\psi}_{2}$ on $\left[0, \delta_{2}\right)$ by

$$
\begin{aligned}
\psi_{2}(t)= & \left(\frac{\int_{0}^{1} \varphi\left((1-\theta) \psi_{1}(t) t\right) d \theta}{1-\varphi_{0}\left(\psi_{1}(t) t\right)}+\frac{\left(\varphi_{0}\left(\psi_{1}(t) t\right)+\varphi_{0}(t)\right) \int_{0}^{1} \varphi_{1}\left(\theta \psi_{1}(t) t\right) d \theta}{\left(1-\varphi_{0}\left(\psi_{1}(t) t\right)\right)\left(1-\varphi_{0}(t)\right)}\right. \\
& \left.+\frac{1}{4}\left[\frac{9\left(\varphi_{0}\left(\psi_{1}(t) t\right)+\varphi_{0}(t)\right)}{1-\varphi_{0}(t)}+\frac{5 \varphi_{1}\left(\psi_{1}(t) t\right)\left(\varphi_{0}\left(\psi_{1}(t) t\right)+\varphi_{0}(t)\right)}{\left(1-\varphi_{0}(t)\right)^{2}}\right] \frac{\int_{0}^{1} \varphi_{1}\left(\theta \psi_{1}(t) t\right) d \theta}{1-\varphi_{0}(t)}\right) \psi_{1}(t)
\end{aligned}
$$

and

$$
\bar{\psi}_{2}(t)=\psi_{2}(t)-1
$$


We obtain $\bar{\psi}_{2}(0)=-1$ and $\bar{\psi}_{2}(t) \rightarrow \infty$ as $t \rightarrow \delta_{2}^{-}$. Denote by $r_{2}$ the smallest solution of Equation $\bar{\psi}_{2}(t)=0$ in $\left(0, \delta_{2}\right)$. Suppose that equation

$$
\varphi_{0}\left(\psi_{2}(t) t\right)=1
$$

has at least one positive solution. Denote by $\delta_{3}$ the smallest such solution. Set $\delta=\min \left\{\delta_{2}, \delta_{3}\right\}$. Define functions $\psi_{3}$ and $\bar{\psi}_{3}$ on the $[0, \delta)$ by

$$
\begin{aligned}
\psi_{3}(t)= & \left(\frac{\int_{0}^{1} \varphi\left((1-\theta) \psi_{2}(t) t\right) d \theta}{1-\varphi_{0}\left(\psi_{2}(t) t\right)}+\frac{\left(\varphi_{0}\left(\psi_{2}(t) t\right)+\varphi_{0}(t)\right) \int_{0}^{1} \varphi_{1}\left(\theta \psi_{2}(t) t\right) d \theta}{\left(1-\varphi_{0}\left(\psi_{2}(t) t\right)\right)\left(1-\varphi_{0}(t)\right)}\right. \\
& \left.+\frac{1}{2}\left[\frac{5\left(\varphi_{0}\left(\psi_{2}(t) t\right)+\varphi_{0}(t)\right)}{1-\varphi_{0}(t)}+\frac{3 \varphi_{1}\left(\psi_{1}(t) t\right)\left(\varphi_{0}\left(\psi_{1}(t) t\right)+\varphi_{0}(t)\right)}{\left(1-\varphi_{0}(t)\right)^{2}}\right] \frac{\int_{0}^{1} \varphi_{1}\left(\theta \psi_{2}(t) t\right) d \theta}{1-\varphi_{0}(t)}\right) \psi_{2}(t)
\end{aligned}
$$

and

$$
\bar{\psi}_{3}(t)=\psi_{3}(t)-1 .
$$

We obtain $\bar{\psi}_{3}(0)=-1$ and $\bar{\psi}_{3}(t) \rightarrow \infty$ as $t \rightarrow \varrho^{-}$. Denote by $r_{3}$ the smallest solution of Equation $\bar{\psi}_{3}(t)=0$ in $(0, \delta)$. Define a radius of convergence $r$ by

$$
r=\min \left\{r_{i}\right\} \quad i=1,2,3, \ldots . .
$$

it follows that for each $t \in[0, r)$

$$
\begin{gathered}
0 \leq \varphi_{0}(t)<1, \\
0 \leq \varphi_{0}\left(\psi_{1}(t) t\right)<1, \\
0 \leq \varphi_{0}\left(\psi_{2}(t) t\right)<1
\end{gathered}
$$

and

$$
0 \leq \psi_{i}(t)<1
$$

Denote by $U(\mu, a)$ the open ball in $B_{1}$ with center $\mu \in B_{1}$ and of radius $a>0$. Moreover, denote by $\bar{U}(\mu, a)$ the closure of $U(\mu, a)$.

The local convergence analysis of Method (2) uses the hypotheses $(\mathrm{H})$ as follows:

$\left(h_{1}\right) \quad F: \Omega \rightarrow B_{2}$ is continuously differentiable operators in the sense of Frèchet and there exists $x_{*} \in \Omega$ such that $F\left(x_{*}\right)=0$ and $F^{\prime}\left(x_{*}\right)^{-1} \in \mathfrak{L}\left(B_{2}, B_{1}\right)$.

$\left(h_{2}\right)$ There exists a function $\varphi_{0}:[0,+\infty) \rightarrow[0,+\infty)$ that is continuous and increasing with $\varphi_{0}(0)=0$ such that for each $x \in \Omega$

$$
\left\|F^{\prime}\left(x_{*}\right)^{-1}\left(F^{\prime}(x)-F^{\prime}\left(x_{*}\right)\right)\right\| \leq \varphi_{0}\left(\left\|x-x_{*}\right\|\right)
$$

and $\delta_{0}$ defined by Equation (3) exists. Set $\Omega_{0}=\Omega \cap U\left(x_{*}, \delta_{0}\right)$.

$\left(h_{3}\right)$ There exist functions $\varphi:\left[0, \delta_{0}\right) \rightarrow[0, \infty)$ and $\varphi_{1}:\left[0, \delta_{0}\right) \rightarrow[0, \infty)$ that are continuous and increasing such that for each $x, y \in \Omega_{0}$

$$
\left\|F^{\prime}\left(x_{*}\right)^{-1}\left(F^{\prime}(y)-F^{\prime}(x)\right)\right\| \leq \varphi(\|y-x\|)
$$

and

$$
\left\|F^{\prime}\left(x_{*}\right)^{-1} F^{\prime}(x)\right\| \leq \varphi_{1}\left(\left\|x-x_{*}\right\|\right) .
$$

$\left(h_{4}\right) \bar{U}\left(x_{*}, r\right) \subseteq \Omega$ and $\delta_{1}$ and $\delta_{2}$ exist and are given by Equations (4) and (5), respectively, and $r$ is defined by Equation (6). 
$\left(h_{5}\right)$ There exists $r_{*} \geq r$ such that

$$
\int_{0}^{1} \varphi_{0}\left(\theta r_{*}\right) d \theta<1
$$

Set $\Omega_{1}=\Omega \cap \bar{U}\left(x_{*}, r_{*}\right)$.

In the sequel, we present local convergence analysis of Method (2) using the preceding notation and the hypotheses $(\mathrm{H})$.

Theorem 1. Suppose that the hypotheses $(H)$ hold and we choose $x_{0} \in U\left(x_{*}, r_{*}\right)-\left\{x_{*}\right\}$. Then, sequence $\left\{x_{n}\right\}$ starting at $x_{0}$ and generated by Method (2) is well defined, remains in $U\left(x_{*}, r\right)$ for every $n=0,1,2 \ldots . .$, and converges to $x_{*}$. Additionally, the following error bounds hold

$$
\begin{aligned}
\left\|y_{n}-x_{*}\right\| & \leq \psi_{1}\left(\left\|x_{n}-x_{*}\right\|\right)\left\|x_{n}-x_{*}\right\| \leq\left\|x_{n}-x_{*}\right\|<r, \\
\left\|z_{n}-x_{*}\right\| & \leq \psi_{2}\left(\left\|x_{n}-x_{*}\right\|\right)\left\|x_{n}-x_{*}\right\| \leq\left\|x_{n}-x_{*}\right\|
\end{aligned}
$$

and

$$
\left\|x_{n+1}-x_{*}\right\| \leq \psi_{3}\left(\left\|x_{n}-x_{*}\right\|\right)\left\|x_{n}-x_{*}\right\| \leq\left\|x_{n}-x_{*}\right\|
$$

where functions $\psi_{i}$ are given previously and $r$ is defined in Equation (6). Furthermore, the limit point $x_{*}$ is only a solution of the equation $F(x)=0$ in $\Omega_{1}$ given in $\left(h_{5}\right)$.

Proof. Estimates (11)-(13) shall be shown using mathematical induction. Let $x \in U\left(x_{*}, r\right)-\left\{x_{*}\right\}$. By Equation (6), $\left(h_{1}\right)$ and $\left(h_{2}\right)$, we have in turn that

$$
\left\|F^{\prime}\left(x_{*}\right)^{-1}\left(F^{\prime}(x)-F^{\prime}\left(x_{*}\right)\right)\right\| \leq \varphi_{0}\left(\left\|x-x_{*}\right\|\right)<\varphi_{0}(r) \leq 1 .
$$

Estimate (14) and the Banach Lemma on invertible operators [2] assure that $F^{\prime}(x)^{-1} \in \mathfrak{L}\left(B_{2}, B_{1}\right)$ and

$$
\left\|F^{\prime}(x)^{-1} F^{\prime}\left(x_{*}\right)\right\| \leq \frac{1}{1-\varphi_{0}\left(\left\|x-x_{*}\right\|\right)} .
$$

It also follows that, for $x=x_{0}$, iterates $y_{0}, z_{0}$, and $x_{1}$ are well defined by Method (2) for $n=0$. We obtain from the first substep of Method (2) for $n=0$ and $\left(h_{1}\right)$ that

$$
y_{0}-x_{*}=x_{0}-x_{*}-F^{\prime}\left(x_{0}\right)^{-1} F\left(x_{0}\right),
$$

so by Equations (6), (10) (for $i=1),\left(h_{3}\right),(15)$, and (16), we obtain in turn that

$$
\begin{aligned}
\left\|y_{0}-x_{*}\right\| & \leq\left\|F^{\prime}\left(x_{0}\right)^{-1} F^{\prime}\left(x_{*}\right)\right\|\left\|\int_{0}^{1} F^{\prime}\left(x_{*}\right)^{-1}\left(F^{\prime}\left(x_{*}+\theta\left(x_{0}-x_{*}\right)\right)-F^{\prime}\left(x_{0}\right)\right)\left(x_{0}-x_{*}\right) d \theta\right\| \\
& \leq \frac{\int_{0}^{1} \varphi\left((1-\theta)\left\|x_{0}-x_{*}\right\|\right) d \theta\left\|x_{0}-x_{*}\right\|}{1-\varphi_{0}\left(\left\|x_{0}-x_{*}\right\|\right)} \\
& =\psi_{1}\left(\left\|x_{0}-x_{*}\right\|\right)\left\|x_{0}-x_{*}\right\| \leq\left\|x_{0}-x_{*}\right\|<r,
\end{aligned}
$$

which shows Equation (11) for $n=0$ and $y_{0} \in U\left(x_{*}, r\right)$. The second substep of the method can be written as

$$
\begin{gathered}
z_{0}-x_{*}=\left(y_{0}-x_{*}-F^{\prime}\left(y_{0}\right)^{-1} F\left(y_{0}\right)\right)+\left(F^{\prime}\left(y_{0}\right)^{-1}-F^{\prime}\left(x_{0}\right)^{-1}\right) F\left(y_{0}\right) \\
-\frac{1}{4}\left[9\left(I-Q\left(x_{0}\right)\right)-5 Q\left(x_{0}\right)\left(I-Q\left(x_{0}\right)\right)\right] Q\left(x_{0}\right) .
\end{gathered}
$$


Then, by Equations (6), (10) (for $i=2),(15)$ (for $i=2),(17)$, and (18), we obtain in turn that

$$
\begin{aligned}
\left\|z_{0}-x_{*}\right\| \leq & \| y_{0}-x_{*}-F^{\prime}\left(y_{0}\right)^{-1} F\left(y_{0}\right)+\left(F^{\prime}\left(y_{0}\right)^{-1}-F^{\prime}\left(x_{0}\right)^{-1}\right) F\left(y_{0}\right) \\
& +\frac{1}{4}\left[9\left(I-Q\left(x_{0}\right)\right)+5 Q\left(x_{0}\right)\left(I-Q\left(x_{0}\right)\right)\right] Q\left(x_{0}\right) \| \\
\leq & \left\|y_{0}-x_{*}-F^{\prime}\left(y_{0}\right)^{-1} F\left(y_{0}\right)\right\|+\left\|F^{\prime}\left(y_{0}\right)^{-1} F^{\prime}\left(x_{*}\right)\right\|\left[\left\|F^{\prime}\left(x_{*}\right)^{-1}\left(F^{\prime}\left(y_{0}\right)-F^{\prime}\left(x_{*}\right)\right)\right\|\right. \\
& \left.+\left\|F^{\prime}\left(x_{*}\right)^{-1}\left(F^{\prime}\left(x_{0}\right)-F^{\prime}\left(x_{*}\right)\right)\right\|\right]\left\|F^{\prime}\left(x_{0}\right)^{-1} F^{\prime}\left(x_{*}\right)\right\| \\
& +\frac{1}{4}\left[9\left\|I-Q\left(x_{0}\right)\right\|+5\left\|Q\left(x_{0}\right)\right\|\left\|I-Q\left(x_{0}\right)\right\|\right]\left\|Q\left(x_{0}\right)\right\| \\
\leq & {\left[\frac{\int_{0}^{1} \varphi\left((1-\theta)\left\|y_{0}-x_{*}\right\|\right) d \theta\left\|y_{0}-x_{*}\right\|}{1-\varphi_{0}\left(\left\|y_{0}-x_{*}\right\|\right)}\right.} \\
& \left.+\frac{\left(\varphi_{0}\left(\left\|y_{0}-x_{*}\right\|\right)+\varphi_{0}\left(\left\|x_{0}-x_{*}\right\|\right)\right) \int_{0}^{1} \varphi_{1}\left(\theta\left\|y_{0}-x_{*}\right\|\right) d \theta\left\|y_{0}-x_{*}\right\|}{\left(1-\varphi_{0}\left(\left\|y_{0}-x_{*}\right\|\right)\right)\left(1-\varphi_{0}\left(\left\|x_{0}-x_{*}\right\|\right)\right)}\right] \\
& +\frac{1}{4}\left[\frac{9\left(\varphi_{0}\left(\left\|x_{0}-x_{*}\right\|\right)+\varphi_{0}\left(\left\|y_{0}-x_{*}\right\|\right)\right)}{1-\varphi_{0}\left(\left\|x_{0}-x_{*}\right\|\right)}+\frac{5 \varphi_{1}\left(\left\|y_{0}-x_{*}\right\|\right)\left(\varphi_{0}\left(\left\|x_{0}-x_{*}\right\|\right)+\varphi_{0}\left(\left\|y_{0}-x_{*}\right\|\right)\right)}{\left.\left(1-\varphi_{0}-x_{*} \|\right)\right)^{2}}\right] \\
& \times \frac{\int_{0}^{1} \varphi_{1}\left(\theta\left\|y_{0}-x_{*}\right\|\right) d \theta\left\|y_{0}-x_{*}\right\|}{1-\varphi_{0}\left(\left\|x_{0}-x_{*}\right\|\right)} \\
\leq & \psi_{2}\left(\left\|x_{0}-x_{*}\right\|\right)\left\|x_{0}-x_{*}\right\|<r,
\end{aligned}
$$

which shows Equation (14) for $n=0$ and $z_{0} \in U\left(x_{*}, r\right)$, where we also used the definition of $Q\left(x_{0}\right)$ and the estimates

$$
\begin{aligned}
\left\|Q\left(x_{0}\right)\right\|\left\|I-Q\left(x_{0}\right)\right\| \leq & \left\|F^{\prime}\left(x_{0}\right)^{-1} F^{\prime}\left(x_{*}\right)\right\|\left\|F^{\prime}\left(x_{*}\right)^{-1} F^{\prime}\left(y_{0}\right)\right\|\left\|F^{\prime}\left(x_{0}\right)^{-1} F^{\prime}\left(x_{*}\right)\right\| \\
& \times\left[\left\|F^{\prime}\left(x_{*}\right)^{-1}\left(F^{\prime}\left(x_{0}\right)-F^{\prime}\left(x_{*}\right)\right)\right\|+\left\|F^{\prime}\left(x_{*}\right)^{-1}\left(F^{\prime}\left(y_{0}\right)-F^{\prime}\left(x_{*}\right)\right)\right\|\right] .
\end{aligned}
$$

Using the third substep of the method for $n=0$, we can write

$$
\begin{aligned}
x_{1}-x_{*}= & \left(z_{0}-x_{*}-F^{\prime}\left(z_{0}\right)^{-1} F\left(z_{0}\right)\right)+\left(F^{\prime}\left(z_{0}\right)^{-1}-F^{\prime}\left(x_{0}\right)^{-1}\right) F\left(z_{0}\right) \\
& -\left[\frac{5}{2} I-Q\left(x_{0}\right)\left(4 I-\frac{3}{2} Q\left(x_{0}\right)\right)\right] F^{\prime}\left(x_{0}\right)^{-1} F\left(z_{0}\right) \\
= & \left(z_{0}-x_{*}-F^{\prime}\left(z_{0}\right)^{-1} F\left(z_{0}\right)\right)+F^{\prime}\left(z_{0}\right)^{-1}\left[\left(F^{\prime}\left(x_{0}\right)-F^{\prime}\left(x_{*}\right)\right)+\left(F^{\prime}\left(x_{*}\right)-F^{\prime}\left(z_{0}\right)\right)\right] F\left(z_{0}\right) \\
& -\frac{1}{2}\left[5\left(I-Q\left(x_{0}\right)\right)-3 Q\left(x_{0}\right)\left(I-Q\left(x_{0}\right)\right)\right] F^{\prime}\left(x_{0}\right)^{-1} F\left(z_{0}\right) .
\end{aligned}
$$

Then, using Equations (6), (10) (for $i=3)$, (15) (for $\left.x=z_{0}\right)$, (17), (19), and (20), we have in turn as in Equation (19) that

$$
\begin{aligned}
\left\|x_{1}-x_{*}\right\| & \leq\left(\frac{\int_{0}^{1} \varphi\left((1-\theta)\left\|z_{0}-x_{*}\right\|\right) d \theta}{1-\varphi_{0}\left(\left\|z_{0}-x_{*}\right\|\right)}+\frac{\left(\varphi_{0}\left(\left\|z_{0}-x_{*}\right\|\right)+\varphi_{0}\left(\left\|x_{0}-x_{*}\right\|\right)\right) \int_{0}^{1} \varphi_{1}\left(\theta\left\|z_{0}-x_{*}\right\|\right) d \theta}{\left(1-\varphi_{0}\left(\left\|z_{0}-x_{*}\right\|\right)\right)\left(1-\varphi_{0}\left(\left\|x_{0}-x_{*}\right\|\right)\right)}\right. \\
& +\frac{1}{2}\left[\frac{5\left(\varphi_{0}\left(\left\|x_{0}-x_{*}\right\|\right)+\varphi_{0}\left(\left\|y_{0}-x_{*}\right\|\right)\right)}{1-\varphi_{0}\left(\left\|x_{0}-x_{*}\right\|\right)}+\frac{3 \varphi_{1}\left(\left\|y_{0}-x_{*}\right\|\right)\left(\varphi_{0}\left(\left\|x_{0}-x_{*}\right\|\right)+\varphi_{0}\left(\left\|y_{0}-x_{*}\right\|\right)\right)}{\left(1-\varphi_{0}\left(\left\|x_{0}-x_{*}\right\|\right)\right)^{2}}\right] \\
& \left.\times \frac{\int_{0}^{1} \varphi_{1}\left(\theta\left\|z_{0}-x_{*}\right\|\right) d \theta}{1-\varphi_{0}\left(\left\|x_{0}-x_{*}\right\|\right)}\right)\left\|z_{0}-x_{*}\right\| \\
& \leq \psi_{3}\left(\left\|x_{0}-x_{*}\right\|\right)\left\|x_{0}-x_{*}\right\| \leq\left\|x_{0}-x_{*}\right\|<r,
\end{aligned}
$$

which shows Equation (2) for $n=0$ and $x_{1} \in U\left(x_{*}, r\right)$. The induction for Equations (11)-(13) is finished, by simply replacing $x_{0}, y_{0}, z_{0}$ and $x_{1}$ by $x_{m}, y_{m}, z_{m}$ and $x_{m+1}$ in the preceding estimates. Then, using the estimate

$$
\left\|x_{m+1}-x_{*}\right\| \leq c\left\|x_{m}-x_{*}\right\|<r
$$


where $c=\psi_{3}\left(\left\|x_{0}-x_{*}\right\|\right) \in[0,1)$, we deduce that $\lim _{m \rightarrow \infty} x_{m}=x_{*}$ and $x_{m+1} \in U\left(x_{*}, r\right)$. Finally, in order to show the uniqueness part, let $y_{*} \in \Omega_{1}$ with $F\left(y_{*}\right)=0$. Define $G=\int_{0}^{1} F^{\prime}\left(x_{*}+\theta\left(y_{*}-x_{*}\right)\right) d \theta$. Then, using $\left(h_{2}\right)$ and $\left(h_{5}\right)$ we obtain in turn that

$$
\begin{aligned}
\left\|F^{\prime}\left(x_{*}\right)^{-1}\left(G-F^{\prime}\left(x_{*}\right)\right)\right\| & \leq \int_{0}^{1} \varphi_{0}\left(\theta\left\|x_{*}-y_{*}\right\|\right) d \theta \\
& \leq \int_{0}^{1} \varphi_{0}(\theta r) d \theta<1
\end{aligned}
$$

so $G^{-1} \in \mathfrak{L}\left(B_{2}, B_{1}\right)$ by the identity

$$
0=F\left(y_{*}\right)-F\left(x_{*}\right)=G\left(y_{*}-x_{*}\right) .
$$

Hence, we conclude by Equation (24) that $x_{*}=y_{*}$.

\section{Numerical Results}

Example 1. Consider the motivational example as given in the introduction of the paper. Note that $x_{*}=\frac{1}{\pi}$ is zero of this function. By conditions $\left(h_{1}\right)-\left(h_{3}\right)$, we can choose $\varphi_{0}(t)=L t, \varphi(t)=L t$, and $\varphi_{1}(t)=\frac{L}{2}$, where $L=\frac{2}{2 \pi+1}\left(80+16 \pi+(11+12 \log 2) \pi^{2}\right)$. Using the definition, we obtain the parameter values as

$$
r_{1}=7.5648 \times 10^{-3}, r_{2}=2.9838 \times 10^{-4}, r_{3}=7.0615 \times 10^{-5} \text { and } r=7.0615 \times 10^{-5} .
$$

Example 2. Let $X=Y=\mathbb{R}^{3}, \Omega=\bar{U}(0,1), x_{*}=(0,0,0)^{T}$. Define function $F$ on $\Omega$ for $w=(x, y, z)^{T}$ by

$$
F(w)=\left(e^{x}-1, \frac{e-1}{2} y^{2}+y, z\right)^{T} .
$$

The Fréchet-derivative is given by

$$
F^{\prime}(w)=\left[\begin{array}{ccc}
e^{x} & 0 & 0 \\
0 & (e-1) y+1 & 0 \\
0 & 0 & 1
\end{array}\right]
$$

Then, we have by conditions $\left(h_{1}\right)-\left(h_{3}\right)$,

$$
\varphi_{0}(t)=(e-1) t, \varphi(t)=e^{\frac{1}{e-1}} t, \varphi_{1}(t)=e^{\frac{1}{e-1}} .
$$

Using the definition of the radius of Equation (6), the parameter values are given as

$$
r_{1}=0.382692, r_{2}=0.146424, r_{3}=0.0971542 \text { and } r=0.0971542
$$

Example 3. Consider function $F$ defined on $\Omega=(-\infty,+\infty)$ by

$$
F(x)=\sin x .
$$

Then, as in the previous examples, we have the following for $x_{*}=0$ :

$$
\varphi_{0}(t)=t, \varphi(t)=t, \varphi_{1}(t)=1 \text {. }
$$

The parameter values are given as

$$
r_{1}=0.666667, r_{2}=0.321702, r_{3}=0.238606 \text { and } r=0.238606 \text {. }
$$


Example 4. Let $B_{1}=B_{2}=C[0,1]$ be the space of continuous functions defined on $[0,1]$ and equipped with the max norm. Let $\Omega=\bar{U}(0,1)$. Define function $F$ on $\Omega$ by

$$
F(\varphi)(x)=\varphi(x)-10 \int_{0}^{1} x \theta \varphi(\theta)^{3} d \theta .
$$

We have that

$$
F^{\prime}(\varphi(\xi))(x)=\xi(x)-30 \int_{0}^{1} x \theta \varphi(\theta)^{2} \xi(\theta) d \theta, \text { for each } \xi \in \Omega .
$$

Similarly, to the previous examples, we get that $x_{*}=0, \varphi_{0}(t)=15 t, \varphi(t)=30 t, \varphi_{1}(t)=30$. Then, we obtain

$$
r_{1}=3.33333 \times 10^{-2}, r_{2}=1.78413 \times 10^{-3}, r_{3}=5.36379 \times 10^{-4} \text { and } r=5.36379 \times 10^{-4} .
$$

\section{Conclusions}

In the forgoing study, we have studied the local convergence of an efficient eighth-order method by assuming conditions only on the first derivative of the operator. The iterative scheme does not use second or higher-order derivative of the considered function. However, in an earlier study of convergence, the hypotheses used were based on Taylor series expansions reaching up to the eighthor higher-order derivatives of function, although the iterative scheme uses first-order derivative. These conditions restrict the usage of the iterative scheme. We have extended the suitability of the method by considering suppositions only on the first-order derivative. The local convergence we have studied is also important in the sense that it provides estimates on the radius of convergence and the error bounds of the solution. Such estimates are not provided in the procedures that use Taylor expansions of higher derivatives, which may not exist or may be very expensive to compute. We have also verified the theoretical results so derived on some numerical problems.

Author Contributions: Methodology, J.R.S.; Writing—review \& editing, J.R.S.; Conceptualization, I.K.A.; Formal analysis, I.K.A.; Investigation, S.K.; Data Curation, S.K.

Conflicts of Interest: The authors declare no conflict of interest.

\section{References}

1. Hoffman, J.D. Numerical Methods for Engineers and Scientists; McGraw-Hill Book Company: New York, NY, USA, 1992.

2. Argyros, I.K.; Magreñán, A.A. Iterative Methods and Their Dynamics with Applications; CRC Press: New York, NY, USA, 2017.

3. Sharma, J.R.; Arora, H. Improved Newton-like methods for solving systems of nonlinear equations. SeMA J. 2017, 74, 147-163. [CrossRef]

4. Amat, S.; Busquier, S.; Gutiérrez, J.M. Third-order iterative methods with applications to Hammerstein equations: A unified approach. J. Comput. Appl. Math. 2011, 235, 2936-2943. [CrossRef]

5. Amat, S.; Hernández, M.A.; Romero, N. Semilocal convergence of a sixth-order iterative method for quadratic equations. Appl. Numer. Math. 2012, 62, 833-841. [CrossRef]

6. Argyros, I.K.; Hilout, S. Weaker conditions for the convergence of Newton's method. J. Complex. 2002, 28, 364-387. [CrossRef]

7. Argyros, I.K.; Ren, H. Improved local analysis for certain class of iterative methods with cubic convergence. Numer. Algorithms 2012, 59, 505-521.

8. Argyros, I.K.; Sharma, J.R.; Kumar, D. Ball convergence of Newton-Gauss method in Banach spaces. SeMA. J. 2016, 74, 429-439. [CrossRef]

9. Argyros, I.K.; Behl, R.; Motsa, S.S. Local convergence of an optimal eighth-order method under weak conditions. Algorithms 2015, 8, 645-655. [CrossRef] 
10. Argyros, I.K.; George, S. Extended local convergence analysis of inexact Gauss-Newton method for singular systems of equations under weak conditions. Stud. Univ. Babeş-Bolyai Math. 2017, 62, 543-558. [CrossRef]

11. Babajee, D.K.R.; Dauhoo, M.Z.; Darvishi, M.T.; Barati, A. A note on the local convergence of iterative methods based on Adomian decomposition method and 3-node quadrature rule. Appl. Math. Comput. 2008, 200, 452-458. [CrossRef]

12. Chun, C.; Stănică, P.; Neta, B. Third-order family of methods in Banach spaces. Comput. Math. Appl. 2011, 61, 1665-1675. [CrossRef]

13. Ezquerro, J.A.; Hernández, M.A. Recurrence relation for Chebyshev-type methods. Appl. Math. Optim. 2000, 41, 227-236. [CrossRef]

14. Gutiérrez, J.M.; Magreñán, A.A.; Romero, N. On the semilocal convergence of Newton-Kantrovich method under center-Lipschitz conditions. Appl. Math. Comput. 2013, 221, 79-88.

15. Jaiswal, J.P. Semilocal convergence of an eighth-order method in Banach spaces and its computational efficiency. Numer. Algorithms 2016, 71, 933-951. [CrossRef]

16. Ren, $\mathrm{H} . ; \mathrm{Wu}, \mathrm{Q}$. Convergence ball and error analysis of a family of iterative methods with cubic convergence. Appl. Math. Comput. 2009, 209, 369-378. [CrossRef]

17. Bi, W.; Wu, Q.; Ren, H. A new family of eight-order iterative methods for solving nonlinear equations. Appl. Math. Comput. 2009, 214, 236-245.

(C) 2018 by the authors. Licensee MDPI, Basel, Switzerland. This article is an open access article distributed under the terms and conditions of the Creative Commons Attribution (CC BY) license (http:/ / creativecommons.org/licenses/by/4.0/). 